\title{
Composite Bonded Magnets With Self-Recoverability for Miniaturized Anisotropic Magnet Rotor
}

\author{
Fumitoshi Yamashita $^{1}$, Osamu Yamada ${ }^{1}$, Shiho Ohya ${ }^{1}$, Osamu Kobayashi ${ }^{1}$, Masaki Nakano ${ }^{2}$, and \\ Hirotoshi Fukunaga ${ }^{2}$ \\ ${ }^{1}$ Rotary Component Technology Development Division, Minebea Co., Ltd., Shizuoka 437-1193, Japan \\ ${ }^{2}$ Faculty of Engineering, Nagasaki University, Nagasaki, 852-8521, Japan
}

\begin{abstract}
In the preparation of a miniaturized rotor, a composite bonded magnet was fabricated by taking advantage of self-recoverability. A preformed magnet was synthesized by using incomplete three-dimensional network molecular structure which was formed under the optimum conditions at a temperature of $433 \mathrm{~K}$, an alignment field of $1.4 \mathrm{MA} / \mathrm{m}$, and a low compacting pressure of $50 \mathrm{MPa}$, respectively. The preformed ones were extruded and compressed into a ring-shaped magnet by using the self-recoverability at a pressure of 200 MPa and a temperature of $423 \mathrm{~K}$ under non-alignment-field. Through the process, a composite bonded magnet rotor in the shape of a ring could be prepared without a bonding layer. It was clarified that a 4 pole/6 slot DC brush less motor can be obtained by using the ring-shaped rotor comprising a parallel oriented anisotropic magnet with $7 \mathrm{~mm}$ in outer diameter, $158 \mathrm{~kJ} / \mathrm{m}^{3}$ in $(\mathrm{BH})$ max, and 6.2 $\mathrm{Mg} / \mathrm{m}^{3}$ in density, respectively. Resultantly, the developed rotor enabled us to increase the $\mathrm{S}$-T gradient by 1.75 times compared with that for a conventional isotropic Nd-Fe-B bonded magnet rotor with the same dimensions.
\end{abstract}

Index Terms-Anisotropic bonded magnet rotor, anisotropic rare earth bonded magnet, DC brushless motor, self-recoverable binder system.

\section{INTRODUCTION}

$\mathbf{I}$ SOTROPIC ring-shaped Nd-Fe-B bonded-magnets with the outer diameter and $(\mathrm{BH})_{\max }$ value of less than $25 \mathrm{~mm}$ and $80 \mathrm{~kJ} / \mathrm{m}^{3}$, respectively, have been prepared by a melt-spinning method followed by a compacting technique and applied to various small motors for electronic devices. In addition, a development of anisotropic magnets with superior magnetic properties such as $160 \mathrm{~kJ} / \mathrm{m}^{3}$ in $(\mathrm{BH})_{\max }$ value are strongly required in order to reduce the current consumption and to achieve further miniaturization in a small motor. Although an adoption of an anisotropic rare-earth iron boride or a nitride material is one of promising methods for preparing radially-anisotropic ring-shaped magnets applied for small motors, it is generally said that a drastic reduction in the remanence occurs as the diameter of a radially-anisotropic multi-polarly ring-shaped magnet becomes smaller than $10 \mathrm{~mm}$ in outer diameter. Anisotropic bonded magnets, therefore, have not been used in small motors up to now.

In order to overcome the above-mentioned difficulty, we developed a new technique using the self-recoverability of a binder which enabled us to form the incomplete three-dimensional (3-D) network molecular structure. Through an investigation on the conditions to achieve the self-recoverability, we obtained an optimized one at a temperature of 433 $\mathrm{K}$, an alignment field of $1.4 \mathrm{MA} / \mathrm{m}$ and a compacting pressure of $50 \mathrm{MPa}$, respectively [1], [2]. The range of the properties in the obtained preformed magnets was $156-180 \mathrm{~kJ} / \mathrm{m}^{3}$ in $(\mathrm{BH})_{\max }$ and $6.1-6.2 \mathrm{Mg} / \mathrm{m}^{3}$ in density. Subsequently, the preformed magnets were transformed into a ring-shaped magnet by using the self-recoverability without an alignment field. Through

Manuscript received October 31, 2009; revised January 08, 2010; accepted January 11, 2010. Current version published May 19, 2010. Corresponding author: F. Yamashita (e-mail: fmtsymst@minebea.co.jp; y2m3st_33@nifty.com).

Color versions of one or more of the figures in this paper are available online at http://ieeexplore.ieee.org.

Digital Object Identifier 10.1109/TMAG.2010.2041050 the process, the magnetic properties did not degrade, and the anisotropic phenomenon agreed with the results shown in previous reports [3]-[6].

In this report, we succeeded in the miniaturization of a ringshaped magnet rotor up to $7 \mathrm{~mm}$. It was also found that an increase in the alignment degree enables us to enhance remanence together with the $(\mathrm{BH})_{\max }$ value as the coercivity value of a $\mathrm{Sm}-\mathrm{Fe}-\mathrm{N}$ fine powder is lower than that of a Nd-Fe-B particle.

We further evaluated the characteristics of a 4 pole 6 slot DC brushless motor with the obtained rotor compared to those of a conventional isotropic Nd-Fe-B bonded magnet rotor with the same dimensions. Consequently, we clarified that the parallelaligned anisotropic magnets prepared by using the self-recoverability can be applied to a miniaturized DC brushless motor comprising a multi-polarly magnetized rotor.

\section{EXPERIMENTAL PROCEDURE}

\section{A. Materials}

Starting materials were six Reduction and Diffusion (RD) $\mathrm{Sm}-\mathrm{Fe}-\mathrm{N}$ fine powders $(2-3 \mu \mathrm{m}$ in particle size, $0.77-1.01$ $\mathrm{MA} / \mathrm{m}$ in intrinsic coercivity, $\mathrm{iHc}_{\mathrm{PS}}$, and $1.22-1.28 \mathrm{~T}$ in remanence, $\mathrm{Mr}_{\mathrm{PS}}$ ) [7] and one Hydrogenation, Disproportionation, De-sorption, and Re-combination (HDDR) Nd-Fe-B particle $(100 \mu \mathrm{m}$ in average particle size, $1.15 \mathrm{MA} / \mathrm{m}$ in intrinsic coecivity, $\mathrm{iHc}_{\mathrm{PN}}$, and $1.32 \mathrm{~T}$ in remanence, $\mathrm{Mr}_{\mathrm{PN}}$ ) [8]. Solid epoxy-oligomer, linear polymer (polyamide), and imidazole-adduct incomplete was used to form a 3-D network molecular structure. In addition, pentaerythritol-stearic-triester $\left(\mathrm{HO}-\mathrm{CH}_{2}\right)-\mathrm{C}-\left[\mathrm{OOC}-\left(\mathrm{CH}_{2}\right)_{16} \mathrm{CH}_{3}\right]_{3}$ was used as a slip-agent. In order to prepare a preformed magnet and a miniaturized rotor magnet, respectively, the self-recoverable binder system was formed by taking advantage of all the above-mentioned organic matter.

\section{B. Preparation Processes}

Fig. 1 shows a schematic representation of the incomplete 3-D network molecular structure for the self-recoverable technique. Through the preparation processes of the preformed 


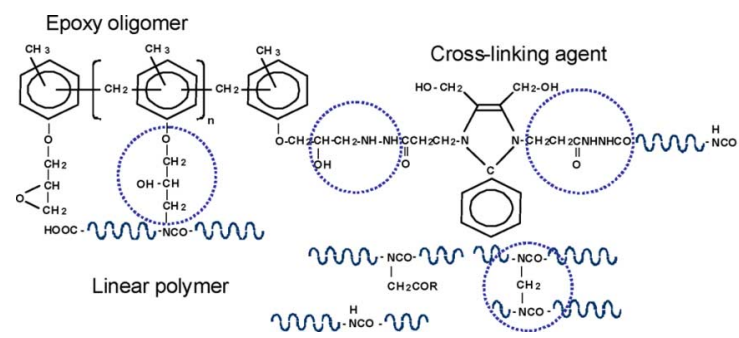

Fig. 1. Incomplete 3-D network molecular structure of the self-recoverable binder system The doted circles denote the cross-linking points of a 3-D network.

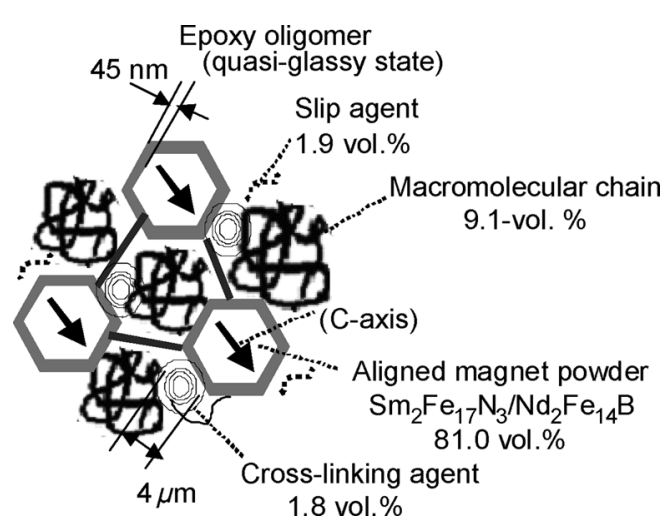

Fig. 2. Schematic representation of the microstructure in matrix of the magnet with the self-recoverable binder system [4].

magnet and consolidated into ring shaped magnet rotor, the macromolecular-chain in a linear polymer was not in the gelation state and synthesized an incomplete 3-D network for self-recoverability at an elevated temperature.

The detailed mechanism was as follows. The compound (volume ratio of the Sm-Fe-N and $\mathrm{Nd}-\mathrm{Fe}-\mathrm{B}$ was $4: 6$, and those magnetic material including 80.7 vol. \% was compacted into a performed magnet under a pressure of $50 \mathrm{MPa}$ at an elevated temperature of $433 \mathrm{~K}$. In the processing stage, the two kinds of magnetic materials in the compound were aligned by applying a transverse magnetic field of $1.4 \mathrm{MA} / \mathrm{m}$ during the compaction. During the process, the cross-linking point was formed with the main cross-linking reaction by using epoxy group and imidazole-adduct together with the side reaction by using epoxy group and amino active hydrogen (-NHCO-) of poly-amide. The majority of macromolecular-chain of poly-amide, however, was not in the gelation state and synthesized the incomplete 3-D network molecular structure for self-recoverability as shown in Fig. 1. In addition, Figs. 2 and 3 show the microstructure in matrix of above-mentioned incomplete 3-D network molecular structure schematically, together with a two kinds of flow pattern of macromolecular-chain during deformation.

Subsequently, the obtained preformed magnets were extruded and compressed into a ring-shaped magnet by using the self-recoverability based on the incomplete 3-D network under a pressure of $200 \mathrm{MPa}$ at an elevated temperature of $423 \mathrm{~K}$ without an alignment field.

In the final step of the preparation process, cross-linking reaction of binder was carried out through the heating process at 453 $\mathrm{K}$ for $20 \mathrm{~min}$ in air. The rigid ring-shaped magnet rotor could be prepared from the preformed magnets. Through the process,

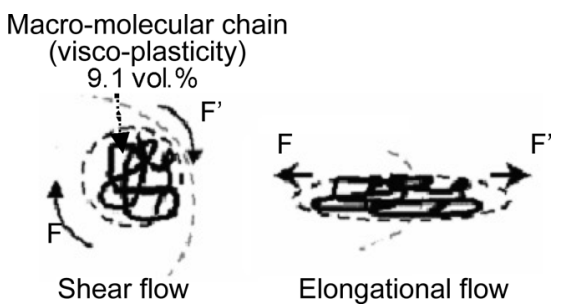

Fig. 3. Schematic representation of two kinds of flow pattern of macromolecular-chain during viscous deformation. The symbols of $\mathrm{F}$ and $\mathrm{F}^{\prime}$ mean the direction of the force during viscous deformation [4].

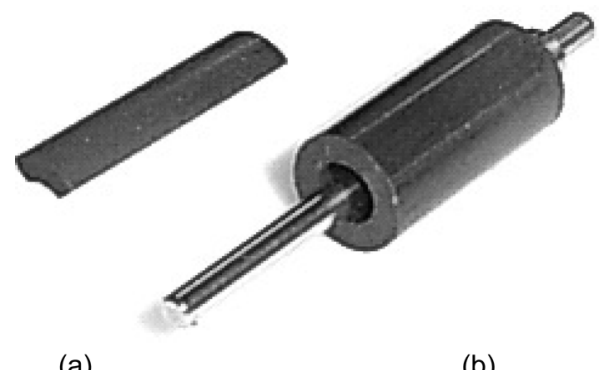

(a)

(b)

Fig. 4. External views of a preformed magnet (a) and a parallel aligned 4-poles magnet rotor (b). The intended dimensions of the magnet rotor were $7 \mathrm{~mm}$ in outer diameter, $3.6 \mathrm{~mm}$ in inner diameter, and $22.5 \mathrm{~mm}$ in length, respectively.

we fabricated a preformed magnet and a parallel aligned 4-poles magnet rotor as shown in Fig. 4. The intended dimensions of the magnet were $7 \mathrm{~mm}$ in outer diameter, $3.8 \mathrm{~mm}$ in inner diameter, and $22.5 \mathrm{~mm}$ in length, respectively.

The self-recoverability, an alignment degree, a magnetic and the mechanical properties as well as DC motor characteristics were evaluated.

\section{RESULTS AND DiscUSSION}

\section{A. Mechanical and Magnetic Properties}

Figs. 5 and 6 show the schematic representation of the cure-last meter method for observation of self-recoverability of a prepared magnet, together with changes in oscillation torque during cross-linking reaction under pressure of $98 \mathrm{kPa}$. In addition, a conventional isotropic Nd-Fe-B based epoxy resin bonded magnet (without macromolecular-chain) and a phenol resin-based compression molding compound were evaluated for comparison. As seen in the Fig. 6, observed torque of the compression molding compound rises with progress of the cross-linking reaction after gelation, and saturated by the end of cross-linking reaction. On the other hand, as for the epoxy resin bonded magnet with complete 3-D network molecular structure, observed torque deteriorates by oscillation after the cross-linking reaction. This decrease of the torque was attributed to the mechanical damage of the slit part of a sample. However, when a composite bonded magnet had an incomplete 3-D network molecular structure, observed torque did not deteriorate even if their cross-linking reaction was final stage as shown in Fig. 5. This fact was attributed to the self-recoverable binder system.

The bending strength of the composite bonded magnet reached $30 \mathrm{MPa}$ at room temperature even if their magnets had bonding layers. It was found the bonding layer does not become a mechanical defect by using self-recoverable binder system. 


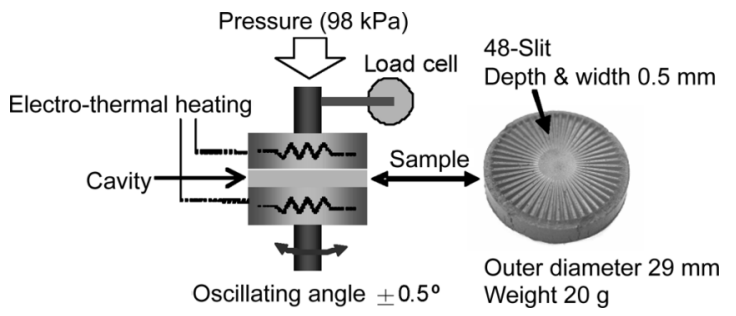

Fig. 5. Schematic representation of the cure-last meter method for observation of self-recoverability under a pressure and an elevated temperature configuration. The sine wave oscillation of the cycle for six seconds were curried out.

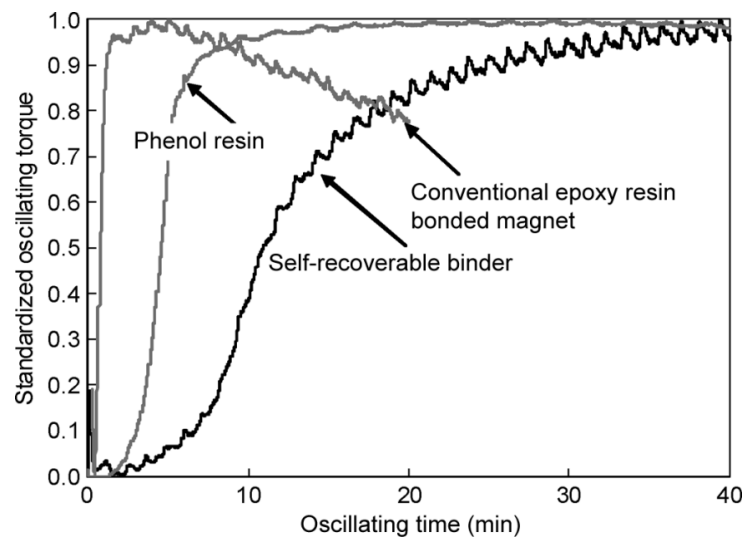

Fig. 6. Changes in oscillation torque by self-recoverability during cross-linking reaction together with those of a conventional isotropic $\mathrm{Nd}-\mathrm{Fe}-\mathrm{B}$ based epoxy resin bonded magnet (without macromolecular-chain) and a phenol resin-based compression molding compound. The oscillating angle and temperature were $\pm 0.5^{\circ}$ and $160^{\circ} \mathrm{C}$, respectively.

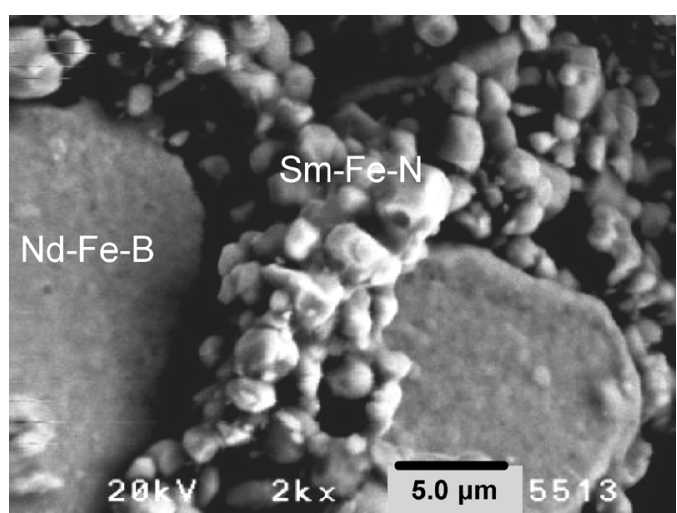

Fig. 7. SEM micrograph of fractured surface of a self-recoverable composite bonded magnet prepared from plural preformed magnets.

The fractured surface of an obtained magnet was examined with a scanning electron microscope (SEM), and the observed surface was shown in Fig. 7. Two kinds of magnetic material were uniformly distributed with good compatibility, suggesting that $\mathrm{Nd}-\mathrm{Fe}-\mathrm{B}$ particles were integrated together with $\mathrm{Sm}-\mathrm{Fe}-\mathrm{N}$ fine powders with a good hybridization. In addition, the bonding layer was not observed. These results indicated the optimized material design including incomplete 3-D network and processes. It was confirmed that the mechanical properties of a magnet including the bonding layers prepared from plural preformed magnets were invulnerable to apply them to a miniaturized rotor.

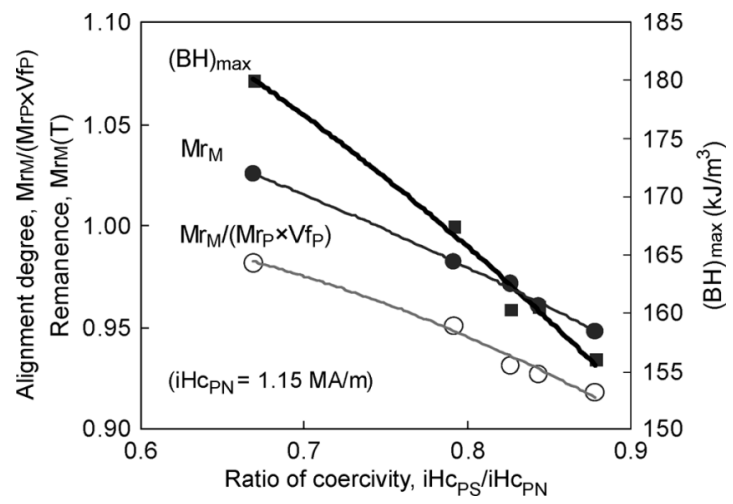

Fig. 8. Alignment degree, $\mathrm{M}_{\mathrm{rM}} /\left(\mathrm{Mr}_{\mathrm{P}} \times \mathrm{Vf}_{\mathrm{P}}\right)$, and $(\mathrm{BH})_{\max }$ value of a com-

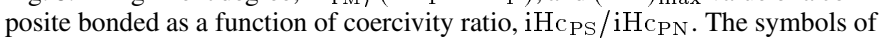

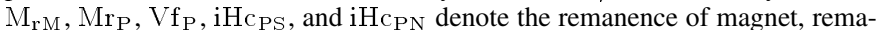
nence of magnetic materials (powder), volume percent of magnetic materials, coercivity of $\mathrm{Sm}-\mathrm{Fe}-\mathrm{N}$, and coercivity of $\mathrm{Nd}-\mathrm{Fe}-\mathrm{B}$, respectively. The $7 \mathrm{~mm}$ cubic magnets were measured with a DC B-H tracer. The maximum field $\mathrm{H}_{\mathrm{m}}$ is \pm 2.4 $\mathrm{MA} / \mathrm{m}$.

Further investigation on the magnetic properties prepared by various $\mathrm{Sm}-\mathrm{Fe}-\mathrm{N}$ fine powders was carried out. In order to evaluate magnetic properties with a $\mathrm{B}-\mathrm{H}$ tracer, cubic specimens with $7 \mathrm{~mm}$ in size were fabricated by using the same process to obtain the preformed magnet. Fig. 8 shows an alignment degree, $\left(\mathrm{Mr}_{\mathrm{M}} /\left(\mathrm{Mr}_{\mathrm{P}} \times \mathrm{Vf}_{\mathrm{P}}\right)\right.$, and $(\mathrm{BH})_{\max }$ of composite bonded magnet as a function of a ratio of coercivity, $\mathrm{iH} c_{\mathrm{PS}} / \mathrm{iH} \mathrm{c}_{\mathrm{PN}}$. Here, $\mathrm{iHc} c_{P N}$ was fixed at $1.15 \mathrm{MA} / \mathrm{m}$ and $i H c_{P S}$ varied from $0.77 \mathrm{MA} / \mathrm{m}$ to $1.01 \mathrm{MA} / \mathrm{m}$. It was found that an increase in the alignment degree enables us to enhance remanence, $\mathrm{Mr}_{\mathrm{M}}$, together with as the coercivity value of a $\mathrm{Sm}-\mathrm{Fe}-\mathrm{N}$ fine powder, $\mathrm{iHc}_{\mathrm{PS}}$, is lower than that of a Nd-Fe-B particle $\left(\mathrm{iHc}_{\mathrm{PN}}\right)$. For example, an alignment degree reached 0.98 as a coercivity value of Sm-Fe-N fine powder was $0.77 \mathrm{MA} / \mathrm{m}$. It was clarified that $1.025 \mathrm{~T}$ of remanence and $180 \mathrm{~kJ} / \mathrm{m}^{3}$ of a $(\mathrm{BH})_{\max }$ can be achieved.

We, further, evaluated that the changes in magnetic properties during deformation process with a B-H tracer, cubic and rectangular specimens with approximately $7 \mathrm{~mm}$ in size were fabricated by using the same processes for the rotor magnet. Here, the rectangular specimen reduced cross section of the pressure axis direction before deformation. Typical magnetic properties of the cubic and rectangular magnets were displayed in Table I. Through the comparison with the magnetic properties between the preformed magnet and final obtained magnet, the deterioration was not detected through the above main process even if the magnets were deformed to widen by $5 \%$ in the pressure axis direction.

\section{B. Rotor and Motor Characteristics}

The values of a static magnetic field for the obtained rotor with $7 \mathrm{~mm}$ in outer diameter (see Fig. 4) could be improved by higher than $143 \%$ compared with those of a conventional isotropic $\mathrm{Nd}-\mathrm{Fe}-\mathrm{B}$ bonded magnet rotor with the same dimensions. The ratio of the static magnetic field in the same magnetic circuit was proportional to the square root of the ratio of $(\mathrm{BH})_{\max }$ of the different magnet. Therefore, the above obtained rotor magnet kept with approximately $160 \mathrm{~kJ} / \mathrm{m}^{3}$ in $(\mathrm{BH})_{\max }$ value even if the magnets were miniaturized up to $7 \mathrm{~mm}$ in outer diameter. 
TABLE I

Changes in Magnetic Properties and Density of a Composite Bonded MAGNet THROUGH a DEFORMATION PROCESS

\begin{tabular}{|c|c|c|c|c|}
\hline & Unit & Preformed magnet & Rotor magnet \\
\hline \multirow{4}{*}{ Properties } & Remanence, $\mathrm{Mr}$ & $\mathrm{T}$ & 0.947 & 0.961 \\
\cline { 2 - 5 } & Coercivity, iHc & $\mathrm{kA} / \mathrm{m}$ & 1003 & 1015 \\
\cline { 2 - 5 } & Coercivity, $\mathrm{bHc}$ & $\mathrm{kA} / \mathrm{m}$ & 596 & 597 \\
\cline { 2 - 5 } & $(\mathrm{BH}) \mathrm{max}$ & $\mathrm{kJ} / \mathrm{m}^{3}$ & 156 & 158 \\
\cline { 2 - 5 } & Density & $\mathrm{Mg} / \mathrm{m}^{3}$ & 5.89 & 6.11 \\
\hline \multirow{3}{*}{ Conditions } & Temperature & $\mathrm{K}$ & 433 & 423 \\
\cline { 2 - 5 } & Filed & $\mathrm{MA} / \mathrm{m}$ & 1.4 & 0 \\
\cline { 2 - 5 } & Pressure & $\mathrm{MPa}$ & 50 & 200 \\
\hline
\end{tabular}

The values of $i \mathrm{Hc}_{\mathrm{PS}} / \mathrm{iHc}_{\mathrm{PN}}, \mathrm{Vf}_{\mathrm{P}}, \mathrm{Mr}_{\mathrm{P}}$, and $\mathrm{Mr}_{\mathrm{M}} /\left(\mathrm{Mr}_{\mathrm{P}} \times \mathrm{Vf}_{\mathrm{P}}\right)$ of magnet are $0.918,0.807,1.28 \mathrm{~T}$, and 0.92 , respectively.

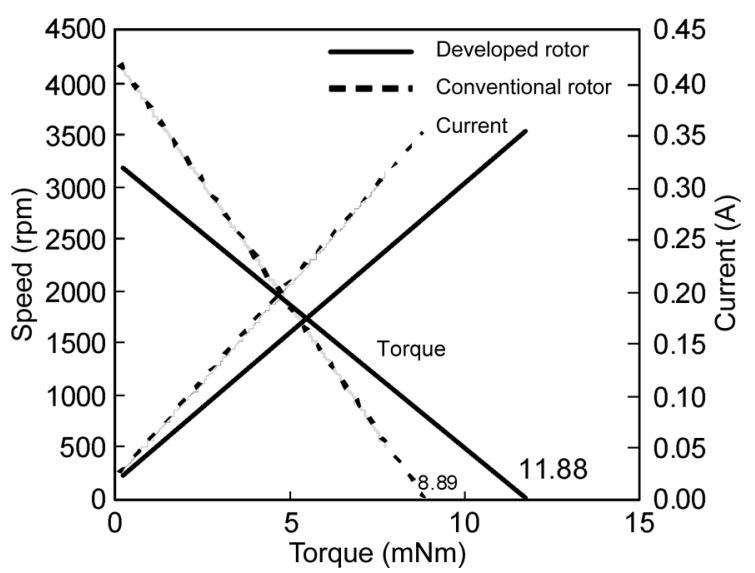

Fig. 9. Characteristics of a 4 pole 6 slot DC brushless motor using composite bonded magnet prepared from self-recoverable technique compared with those for conventional magnet. The conventional magnet rotor used an isotropic $\mathrm{Nd}-\mathrm{Fe}-\mathrm{B}$ bonded magnet with $80 \mathrm{~kJ} / \mathrm{m}^{3}$ of $(\mathrm{BH})_{\max }$.

We, further, investigated the characteristics of a 4 pole 6 slot DC brushless motor comprising the composite magnet together with those of a conventional isotropic Nd-Fe-B bonded magnet rotor as shown in Fig. 9 and Table II. In one example, a starting torque and S-T gradient of the 4 pole 6 slot DC brushless motor could be improved by higher than $134 \%$ and by $175 \%$, respectively, compared with those of a conventional one with the same dimensions. We, further, indicated that the direction of anisotropy can be controlled continuously by using a fixed alignment field together with a mechanical design of the preformed magnets, and their self-recoverability. It was clarified that the anisotropic composite bonded magnets prepared by using the self-recoverability can be applied to a miniaturized DC brushless motor comprising a multi-polarly magnetized rotor.

\section{CONCLUSION}

In this study, the miniaturization of a ring-shaped magnet rotor by using self-recoverability could be achieved by taking advantage of the incomplete 3-D network molecular structure. The obtain results were as follows;

1) The bending strength of the magnet reached $30 \mathrm{MPa}$ at room temperature even if their magnets had the bonding layers.
TABLE II

MOtOR CHARACTERISTICS OF A PREPARED ROTOR TOGETHER With THOSE OF A CONVENTIONAL ISOTROPIC Nd-Fe-B MAGNET

\begin{tabular}{|c|c|c|c|c|}
\hline & Unit & $\begin{array}{c}\text { Anisotropic } \\
\text { composite }\end{array}$ & $\begin{array}{c}\text { Isotropic } \\
\text { NdFeB }\end{array}$ & Ratio \\
\hline Starting torque & $\mathrm{mNm}$ & 11.88 & 8.89 & 1.34 \\
\hline Speed constant, Kn & $\mathrm{rpm} / \mathrm{V}$ & 286.5 & 378.2 & \\
\hline Torque constant, $\mathrm{Kt}$ & $\mathrm{mNm} / \mathrm{A}$ & 33.3 & 25.25 & 1.32 \\
\hline S-T gradient & $\mathrm{mNm} / \mathrm{rpm}$ & 272.6 & 477.4 & $1.75^{*}$ \\
\hline No-load speed & $\mathrm{rpm}$ & 3238 & 4247 & \\
\hline No-load current & $\mathrm{A}$ & 0.0190 & 0.0187 & 1.02 \\
\hline Motor efficiency, $\max$ & $\%$ & 62.28 & 60.37 & 1.03 \\
\hline Motor efficiency, @Pmax & $\%$ & 45.6 & 45.0 & 1.01 \\
\hline Output power, max & $\mathrm{W}$ & 1.012 & 0.9907 & 1.02 \\
\hline
\end{tabular}

Nominal voltage was $12 \mathrm{~V}$ DC, and S-T gradient ratio indicated reciprocal value. The dimensions of 6 slot stator core were $7.4 \mathrm{~mm}$ in inner diameter and $16 \mathrm{~mm}$ in outer diameter, respectively.

2) An alignment degree reached 0.98 when a coercivity ratio of $\mathrm{iHc} \mathrm{CPS}_{\mathrm{iH}} / \mathrm{iHC}_{\mathrm{PN}}$ was 0.67 . It was also found that $1.025 \mathrm{~T}$ of remanence and $180 \mathrm{~kJ} / \mathrm{m}^{3}$ of $(\mathrm{BH})_{\max }$ can be obtained.

3) The values of a static magnetic field for the rotor with $7 \mathrm{~mm}$ in outer diameter could be improved by higher than $143 \%$, and no deterioration of a $(\mathrm{BH})_{\max }$ was detected through the process.

4) The obtained composite magnets can be applied to a small DC brushless motor comprising a multi-polarly magnetized rotor.

\section{ACKNOWLEDGMENT}

This work was supported by the New Energy and Industrial Technology Development Organization (NEDO), under Project P07026 of Japan.

\section{REFERENCES}

[1] F. Yamashita, O. Yamada, S. Ohya, O. Kobayashi, M. Nakano, and H. Fukunaga, "Preparation of ring-shaped composite bonded magnets with continuously controlled anisotropy distribution for internal space," J. Phys., 2010, to be published.

[2] F. Yamashita, O. Yamada, S. Ohya, O. Kobayashi, M. Nakano, and H. Fukunaga, "Thermo-mechanical behavior of self-recoverable composite bonded magnet and their magnetic properties," (in Japanese) $J$. Magn. Soc. Jpn., 2010, to be published.

[3] F. Yamashita, K. Kawamura, Y. Okada, H. Murakami, M. Ogushi, M. Nakano, and H. Fukunaga, "Preparation of ring-shaped rare earth bonded magnets with continuously controlled anisotropy directions," in Proc. 20th Int. Workshop on Rare Earth Permanent Magn. \& Their Appl., Crete, Greece, 2008, pp. 91-94.

[4] F. Yamashita, K. Kawamura, Y. Okada, H. Murakami, M. Ogushi, M. Nakano, and H. Fukunaga, "Composite bonded magnets with controlled anisotropy directions prepared by viscous deformation technique," J. Magn. Magn. Mater., vol. 316, pp. e101-e104, 2007.

[5] F. Yamashita, K. Kawamura, Y. Okada, H. Murakami, M. Ogushi, M. Nakano, and H. Fukunaga, "Preparation method of rare earth bonded magnets with continuously controlled anisotropy directions," J. Appl. Phys., vol. 101, p. 09K522, 2007.

[6] F. Yamashita and H. Fukunaga, "Radially-anisotropic rare-earth hybrid magnet with self-organizing binder consolidated under a heat and a low-pressure configuration," in Proc. 18th Int. Workshop on High Performance Magn. Their Appl., Annecy, France, 2004, pp. 76-83.

[7] A. Kawamoto, T. Ishikawa, S. Yasuda, K. Takeya, K. Ishizaka, T. Iseki, and K. Ohmori, " $\mathrm{Sm}_{2} \mathrm{Fe}_{17} \mathrm{~N}_{3}$ magnet powder made by reduction and diffusion method," IEEE Trans. Magn., vol. 35, pp. 3322-3324, 1999.

[8] T. Takeshita and R. Nakayama, "Magnetic properties and microstructures of the Nd-Fe-B magnetic powders produced by the hydrogen treatment," in Proc. 10th Int. Workshop on Rare Earth Magn. Their Appl., 1989, vol. I, pp. 551-565. 